\title{
The NO TRAIL to YES TRAIL in cancer therapy (Review)
}

\author{
JI YEUN LEE ${ }^{1}$, SARA HUERTA-YEPEZ ${ }^{1}$, MARIO VEGA ${ }^{1}$, STAVROULA BARITAKI ${ }^{1}$, \\ DEMETRIOS A. SPANDIDOS ${ }^{2}$ and BENJAMIN BONAVIDA ${ }^{1}$
}

\author{
${ }^{1}$ Department of Microbiology, Immunology and Molecular Genetics, David Geffen School of Medicine, \\ Jonsson Comprehensive Cancer Center, University of California at Los Angeles, Los Angeles, CA; \\ ${ }^{2}$ Department of Clinical Virology, Faculty of Medicine, University of Crete, Heraklion, Crete, Greece
}

Received June 21, 2007; Accepted July 23, 2007

\begin{abstract}
Treatment of cancer patients with conventional therapies (chemotherapy, hormonal therapy, immunotherapy and radiation) respond initially well and experience prolonged tumor-free survival. However, in many patients tumor recurrences and relapses occur and such tumors exhibit the resistant phenotype i.e. cross-resistance to various cytotoxic and apoptotic agents. Therefore, new therapeutic strategies are currently being explored and are based on a better understanding of the underlying biochemical and molecular mechanisms of tumor cell resistance. Hence, novel sensitizing agents that can modify the tumor dysregulated apoptotic gene products can reverse resistance when used in combination with subtoxic doses of cytotoxic reagents. Targeted antitumor therapies are the current choice in the treatment of resistant tumors. One such targeted therapy is the application of TRAIL or TRAIL agonist monoclonal antibodies (mAbs)
\end{abstract}

Correspondence to: Professor Benjamin Bonavida, Department of Microbiology, Immunology and Molecular Genetics, David Geffen School of Medicine, Jonsson Comprehensive Cancer Center, University of California at Los Angeles, Los Angeles, CA 90095-1747, USA

E-mail: bbonavida@mednet.ucla.edu

Abbreviations: APC, antigen-presenting cells; CDDO-Me, methyl-2-cyano-3,12-dioxooleana-1,9-dien-28-oate; CDDP, cisdiamminedichloroplatinum(II); CHX, cycloheximide; CTL, cytotoxic T lymphocytes; DISC, death-inducing signaling complex; DOX, doxorubicin; FADD, Fas-associated death domain; IL-1ß, interleukin 1ß; iNOS, inducible nitric-oxide synthase; LPS, lipopolysaccharide; MHC, major histocompatibility complex; NK, natural killer cells; NO, nitric oxide; NOS, nitric oxide synthase; NOSII/iNOS, inducible nitric oxide synthase; NOS III/eNOS, endothelial nitric oxide synthase; NOS I/nNOS, neuronal nitric oxidase synthase; $\mathrm{O}_{2}^{-}$, superoxide; $\mathrm{ONOO}^{-}$, peroxynitrite; PARP, poly-ADP ribose polymerase; rTRAIL, recombinant soluble TRAIL; TRAIL, tumor necrosis factor-related apoptosis inducing ligand; YY1, Yin Yang 1

Key words: nitric oxide, TRAIL, sensitization, tumor resistance, Yin Yang 1, DR5, apoptosis
(anti-DR4 and anti-DR5) because, unlike Fas ligand and TNF- $\alpha$, they are not cytotoxic to normal tissues. TRAIL as monotherapy will only be effective against TRAIL sensitive tumors, however, most tumors are resistant to TRAIL and their sensitization can restore their sensitivity to TRAIL apoptosis. We present, herein, one potential novel sensitizing agent, namely, nitric oxide (NO) that has been shown to sensitize TRAIL-resistant tumor cells to TRAIL apoptosis via its inhibitory effect on the transcription factors NF- $\mathrm{\kappa B}$ and Yin Yang 1 (YY1), concomitantly with upregulation of DR5. We propose the therapeutic application of NO donors as sensitizing agents used in combination with TRAIL/DR4 or DR5 mAbs in the treatment of TRAIL-resistant tumors.

\section{Contents}

1. Introduction

2. Immunotherapy mediated by cytotoxic cells/ligands/ antibodies

3. Studies on the application of TRAIL as a new anti-cancer immunotherapeutic

4. Sensitization of TRAIL-resistant tumors to TRAILinduced apoptosis

5. NO-mediated upregulation of DR5 and sensitization to TRAIL

6. Molecular mechanisms of NO-mediated sensitization to TRAIL

7. Future directions/conclusions

\section{Introduction}

Cancer is the second leading cause of death in the world. Chemotherapy, immunotherapy and gamma radiation are examples of anti-cancer therapies currently being utilized for cancer treatments. However, the major problem with tumor cells is their ability to develop resistance to conventional therapeutics over time. Therefore, finding novel therapeutic strategies that will reverse resistance or sensitize resistant tumor cells to chemotherapeutics or immunotherapeutics remains one of the toughest challenges yet to be overcome (1). Several novel approaches have been examined for reversal of tumor cell resistance to conventional therapeutics such as, 
for example, the use of chemotherapeutic agents which upregulate the expression of death receptors $(2,3)$. Antibodymediated immune therapy has been considered a promising candidate for overcoming resistance; for example, agonistic monoclonal antibodies mimic the activity of death ligands and they are able to bind to specific death receptors and target its respective signaling pathways for induction of cell death. Furthermore, using targeted sensitizing agents in combination with cytotoxic drugs show a significant therapeutic potential to directly induce apoptosis in transformed cells $(4,5)$.

While chemotherapy utilizes cytotoxic drugs to kill tumor cells by apoptosis, immunotherapy stimulates the host's own immune system to combat cancer and it is thus less toxic to organs. Chemotherapeutic drugs destroy cancer cells by preventing cells from dividing and replicating, but they can also damage the DNA of normal cells. Unlike healthy cells that are able to recover from chemotherapy once the treatment is completed, cancer cells cannot repair themselves and undergo apoptosis. Over the last couple of years, immunotherapy has gained more attention in the field of research, leading to new developments in the field of cancer treatment. However, immunotherapy has not yet been successful in achieving a significant curative rate and remains in its early stage of experimental approach (4).

\section{Immunotherapy mediated by cytotoxic cells/ligands/ antibodies}

Cytotoxic cells and natural killer cells play important roles in tumor surveillance (6). Besides cell-mediated killing, cytotoxic ligands (e.g. TRAIL) and monoclonal antibodies are examples of different types of immunotherapy that are used to specifically destroy cancer cells while sparing normal cells. Cytotoxic $\mathrm{T}$ lymphocytes belong to the $\mathrm{CD} 8^{+}$subset of $\mathrm{T}$ cells, and they are involved in eliminating target cells by recognizing tumor peptides presented by the major histocompatibility complex (MHC) on the surface of antigenpresenting cells (APC) (6). However, natural killer cells (NK) have the advantage of destroying infected cells without recognizing any specific antigens. There are two killing mechanisms by which CTL and NK cells induce apoptosis, one of which involves the release of granzymes and perforin, and the second involves interaction of TNF ligands (TNF- $\alpha$, FasL, TRAIL) with corresponding death receptors on target cells (7-9). However, resistance to chemotherapy or immunotherapy can also result in cross-resistance to different apoptotic stimuli including chemotherapy, immunotherapy and radiation.

TRAIL belongs to the family of TNF ligands and its expression is upregulated upon activation of lymphocytes $(10,11)$. Unlike its other homologous ligands such as TNF- $\alpha$ and FasL, which are toxic to normal cells, TRAIL can selectively induce apoptosis in tumor cells while leaving normal cells intact (12). TRAIL has five death receptors including DR4, DR5, osteoprotegerin, and two decoy receptors. It has been suggested that TRAIL's selectivity is in part due to the presence of decoy receptors on normal cells that prevent TRAIL from binding to death receptors and undergoing TRAIL-induced apoptosis, whereas TRAIL has an opposite effect on tumor cells (13). However, there are also reports that show that tumor cells express decoy receptors and it is not clear whether the failure of killing normal cells is primarily due to decoy receptors. Although FasL and TNF- $\alpha$ both possess anti-cancer properties, they are highly toxic to normal cells and toxic in vivo. Therefore, treating cancer with TRAIL is preferred because it can kill tumor cells effectively without being lethal to normal cells.

Despite various treatments available that exert anti-tumor effects, cancer cells can acquire the capability to evade apoptosis and immune surveillance. Inactivation of tumor suppressor proteins such as p53, or downregulation of deathinducing ligands such as FasL (10) and TRAIL (14) or development of mechanisms that dyregulate the apoptotic signaling pathways, are among the numerous ways tumor cells can become resistant to apoptosis. Cancer cells can become resistant to chemotherapy by developing mechanisms to repair DNA damage or decreasing the uptake of drugs across the cell wall. While patients in early stages of cancer respond to chemotherapeutic treatments effectively, patients in advanced malignant stage of tumor respond poorly to chemotherapy and apoptosis. Although immunotherapy is much more tumor specific and less organ toxic, cells that are resistant to chemotherapeutics can acquire cross-resistance to immune-mediated killing. Since both approaches involve a central apoptotic pathway, resistance to chemotherapy inevitably results in resistance to tumor killing induced by apoptosis-mediated stimuli (4).

TRAIL has been shown to be useful in exerting antitumor activity alone or in combination with drugs (15-18). Although some tumor cells develop resistance to TRAIL $(4,19-21)$, there are various sensitizing agents such as chemotherapeutic drugs $(19,22)$, cytokines (23), and inhibitors (24) that could mediate the reversal of TRAIL resistance.

Nitric oxide (NO) is an example of a potent anti-cancer agent that can overcome tumor cell resistance (1). NO has many clinically important roles, including its ability to sensitize TRAIL-mediated apoptosis, when used in combination with other cytotoxic agents. Although TRAIL by itself is not effective in treating TRAIL-resistant tumors, other conventional chemotherapeutic drugs and sensitizing agents such as NO have shown to enhance the therapeutic potential of TRAIL $(3,25)$.

TRAIL induces apoptosis in tumor cells by binding to death-apoptotic receptors, TRAIL-R1/DR4 and TRAILR2/DR5 (26). Once trimeric TRAIL cross-links with the receptor DR4 or DR5, there is an aggregation of the death domains, which leads to recruitment of the adaptor molecule FADD and activation of caspase 8-mediated cascade (27). Caspase 8 is responsible for initiating activation of caspase 3 , ultimately committing tumor cells to undergo apoptosis $(28,29)$. In some cases, the mitochondrial type II pathway is involved in TRAIL-induced apoptosis (30). Unlike type I cells (e.g. SKW6.4 and H9) that produce high amounts of caspase 8 independent of the mitochondrial pathway, type II cells (e.g. CEM and Jurkat cells) are dependent on the mitochondria for death receptor-mediated apoptosis (30). Type II cells release cytochrome $\mathrm{C}$ from the mitochondrial intermembrane space into the cytoplasm, forming an apoptosome that activates procaspase 9 (31). Caspase 9 then activates 
caspase 3, which can cleave procaspase 8, resulting in cell death. Type II cells are also characterized by the expression of anti-apoptotic members of Bcl-2 (30).

\section{Studies on the application of TRAIL as a new anti- cancer immunotherapeutic}

Clinically relevant agents increase the expression of TRAIL death receptors and undergo apoptosis by utilizing TRAIL or agonistic antibodies specific to TRAIL death receptors (32). Although TRAIL is a type II transmembrane ligand, the extracellular region can be cleaved off and form a soluble molecule (33). In particular, recombinant TRAIL (rTRAIL) shows anti-tumor activity in vitro and in vivo (15). rTRAIL has been proposed as an effective natural immune molecule for treating patients in cancer trials (34). Unlike other cytokines such as TNF- $\alpha$ and FasL that have been shown to induce toxic effects in non-transformed cells $(35,36)$ and cause inflammation and liver damage (37), rTRAIL does not induce apoptosis in normal human hepatocytes and therefore is being administered clinically to eliminate the tumor (34). Recombinant soluble TRAIL produced by Genentech Incorporated and Amgen (34) has currently entered phase I clinical trials, while agonistic antibodies to anti-DR4 and DR5 have been introduced in phase I and II studies (32). Patients with advanced malignancies who have been tested for phase I trials show no major adverse effect or toxicities to antibody administration except in a few cases with HGSETR2 (TRAIL-R2 mAb) (38-40). Although the clinical trials demonstrate promising results, the use of TRAIL or agonistic anti-TRAIL receptor antibody therapies is only advantageous to patients with TRAIL-sensitive tumors (34). Patients with TRAIL-resistant tumors require the combination of sensitizing agents and TRAIL to reverse resistance.

\section{Sensitization of TRAIL-resistant tumors to TRAIL- induced apoptosis}

TRAIL alone is not effective in treating drug- and TRAILresistant tumors but when it is combined with subtoxic chemotherapeutic drugs the cytotoxicity of TRAIL is significantly enhanced $(2,3)$. Anti-cancer drugs such as ADR, VP-16, and CDDP, that upregulate the expression of death receptors and activate caspase 8/9-mediated cascades, have the potential to treat various cancer types in combination with TRAIL via TRAIL-mediated apoptosis. CDDP is an example of a DNAdamaging agent used in chemotherapy to treat gliomas, one of the most common brain tumors in humans. Malignant gliomas remain incurable partly due to the difficulty of treatment by surgical removal and resistance to irradiation (41). Although CDDP alone is not effective at inducing apoptosis, co-treatment of CDDP with TRAIL demonstrates a significant suppression of tumor growth in vivo (41).

CDDO-Me is another cancer therapeutic agent synthesized from triterpenoids that has been reported to upregulate the expression of DR5 and induce TRAIL-mediated apoptosis in human lung cancer cells (37). CDDO-Me also plays a role in activating the caspase 8 pathway, thus committing cells to programmed death in combination with TRAIL. In neuroblastoma, a solid tumor usually present in childhood, TRAIL- induced apoptosis can be further maximized by treating cells with drugs frequently used in chemotherapy, such as doxorubicin and etoposide (42) that induce DNA-damage. As observed with other anti-cancer agents, cycloheximide or chemotherapeutic drugs have the ability to sensitize neuroblastoma cells to TRAIL-mediated cell death by inducing cell surface expression of DR4 and DR5 (42). Cytotoxic drugs not only increase the formation of apoptotic molecules such as caspase 8, FADD (43), or DISC assembly (44), but also make tumor cells highly sensitive to TRAIL.

\section{NO-mediated upregulation of DR5 and sensitization to TRAIL}

Nitric oxide synthase is an enzyme that oxidizes L-arginine to nitric oxide. NOS exists in three different isoforms, NOSII/iNOS, NOS III/eNOS, and NOS I/nNOS (1). NOS I, which is produced in neuronal tissue, is responsible for contraction of skeletal muscle and cell communication, and it also acts as a neurotransmitter. NOS III is expressed only on the membrane of endothelial cells and generated in blood vessels; it is mainly involved in vascular functions and stimulating angiogenesis. The $\mathrm{Ca}^{2+} / \mathrm{CaM}$ dependent NOS I and NOS III are responsible for maintaining minimal level of NO production in neural and endothelial cells (1). NOS II is the only $\mathrm{Ca}^{2+} / \mathrm{CaM}$-independent isoform that is responsible for producing large amounts of NO in the immune system as a host defense mechanism against pathogens (47). NOS II has been mainly identified in cancer cells, but its expression is not limited to macrophages and epithelial cells. The NOS II promoter has a TATA box containing binding sites for transcription factors at $\sim 900 \mathrm{bp}$ (48). One of the major transcription factors that induce the expression of NOS II is $\mathrm{NF}-\kappa \mathrm{B}$ (49). In studies that tested whether NF-кB has an effect on transcription of NOS II, it was shown that NF-кB does take part in regulating the expression of NOS II $(48,50)$.

$\mathrm{NO}$ is involved in a variety of cellular mechanisms as well as the pathogenesis of human diseases, but it also serves as a novel therapeutic molecule capable of overcoming resistance in tumor cells. NO donors, e.g. DETANONOate, or agents that are able to induce NO are currently used in clinics to treat cardiovascular diseases. In addition, NO donors inhibit angiogenesis in tumor cells via apoptosis on inflammatory cells (1).

$\mathrm{NO}$ can act as an anti-apoptotic or apoptotic modulator depending on its concentration. While high concentrations of NO induce apoptosis, low concentrations of NO prevent the assembly of transcription factors, Apaf-1 and procaspase 9, that are necessary for induction of apoptosis (51). In the case of high concentrations of $\mathrm{NO}, \mathrm{NO}$ can interact with $\mathrm{O}_{2}^{-}$to generate peroxynitrite, $\mathrm{ONOO}^{-}$, which is a powerful radical that can destroy cells. Peroxynitrite can induce membrane depolarization of the mitochondria and release of cytochrome $\mathrm{C}$. Increased amount of ONOO stimulates apoptosis by diffusing through cell walls and inducing DNA damage (47). In the case of tumor cells, the energy required to repair DNA by the DNA repair enzyme, PARP, is too costly and therefore, cells undergo apoptosis (45). 
cysteine thiol S-nitrosylation<smiles>NC(CS)C(=O)O</smiles>

tyrosine nitration<smiles>[R]c1ccc(O)cc1</smiles><smiles>N#CC(N)C(=O)O</smiles>

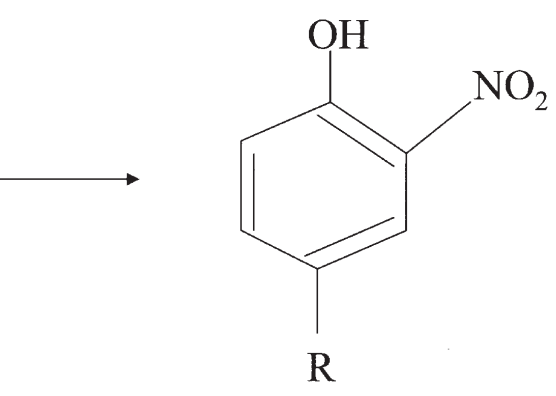

Figure 1. Protein modification by NO. The modification of cysteine-thiol by NO leading to S-nitrosylation. In addition, tyrosine residues can be nitrated.

Besides its association with TRAIL, nitric oxide is also linked to regulating Fas expression and sensitizing carcinoma cell lines to Fas-induced apoptosis. It has been observed that when interferon-gamma (IFN- $\gamma$ ) is used alone or in combination with other cytokines such as interleukin- $1 \beta$ and bacterial lipopolysaccharide (LPS), it leads to the generation of iNOS, which is responsible for production of NO (46). Endogenously produced NO, when stimulated with IFN- $\gamma$, participates in rendering tumor cells susceptible to cytotoxic lymphocyte killing via sensitization to FasL-induced apoptosis (46).

NO also plays a critical role in sensitizing tumor cells to TRAIL via TRAIL-induced apoptosis. When both TRAIL and DETANONOate are used together the mitochondria membrane is depolarized and cytochrome $\mathrm{C}$ and Smac/DIABLO are released into the cytosol (25). Cytochrome $\mathrm{C}$ is involved in inducing apoptosis via a caspase 9-dependent cascade. In addition, a significantly higher activation of procaspase 8 , procaspase 9 , and apoptosis is observed when the two agents are used in combination in comparison to when TRAIL and DETANONOate are used independently (25). Therefore, the therapeutic potential of $\mathrm{NO}$ as a sensitizing agent in combination with TRAIL is promising. Although most cancer cells are resistant to TRAIL-mediated apoptosis, high concentrations of NO generated by DETANONOate can be used to sensitize resistant tumor cells to apoptotic stimuli such as TRAIL. The mechanism by which DETA-NONOate sensitizes cancer cells to TRAIL-mediated apoptosis is via inhibition of the constitutively activated cell survival and anti-apoptotic NF-KB signaling pathway. It has been reported that DETANONOate participates in inactivating NF- $\mathrm{\kappa B}$ by S-nitrosylation (52) and inhibiting the expression of an anti-apoptotic gene, Bcl- $\mathrm{x}_{\mathrm{L}}$, (25) to mediate tumor cell sensitization to TRAIL. In addition, recent findings examined the molecular basis of NO-mediated sensitization of TRAIL resistant tumor cells to TRAIL-mediated apoptosis (see below).

\section{Molecular mechanisms of NO-mediated sensitization to TRAIL}

The molecular mechanism by which NO mediates sensitivity to TRAIL is complex and multi-factorial. Hence, NO inhibits specific transcription factors such as NF- $\mathrm{KB}$ and YY1 (52) via S-nitrosylation. S-nitrosylation is the addition of NO to cysteine-thiol residues (53), and it serves as the quintessential redox-based post-translational protein modification (Fig. 1). $\mathrm{S}$-nitrosylation is critical in regulating protein functions as well as cell signaling transductions; in particular, S-nitrosylation can affect the molecular signaling system associated with cancer, and it can even play a role in prompting or suppressing human diseases (52). The pathways involving S-nitrosylation formation with the zinc-finger transcription factor, Yin Yang 1 (YY1), is critical for inducing NO-mediated apoptosis to TRAIL. YY1 is a DNA binding protein that interacts with DNA using the cysteine residues that lie in the zinc centers. However, NO can interfere with YY1 DNA-binding activity by S-nitrosation of cysteine thiol groups $(54,55)$. Normally, YY1 is a transcription repressor that binds to the silencer region of the Fas promoter and negatively regulates the expression of Fas. However, once YY1 is S-nitrosylated by NO, YY1 loses its activity, and upregulates the expression of Fas. Thus, tumor cells can be sensitized to Fas L-induced apotosis by NO, which promotes S-nitrosylation of YY1 and upregulation of Fas (46). It has been noted that tumor cells overexpress YY1 compared to normal cells (56), and this overexpression might be the cause of resistance of tumor cells to apoptosis or destruction by the immune system (52). 


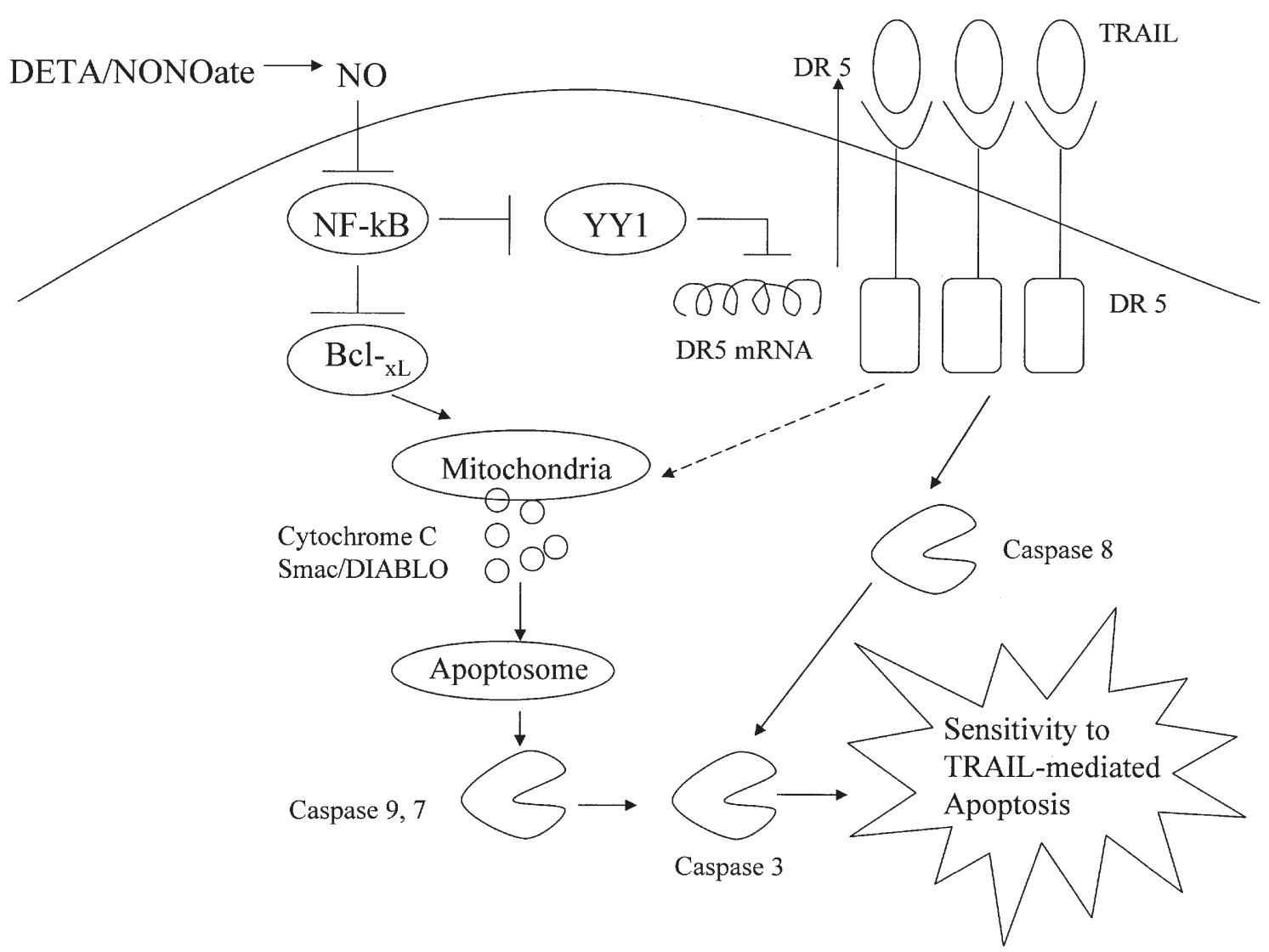

Figure 2. NO sensitizes tumor cells to TRAIL-mediated apoptosis. The effect of treating TRAIL-resistant tumor cells by the nitric oxide donor, DETANONOate, leading to sensitization of tumor cells to TRAIL-mediated apoptosis. Treatment with NO inhibits NF- $\mathrm{B}$ activity and downstream inhibits the anti-apoptotic gene product, Bcl- $\mathrm{x}_{\mathrm{L}}$. This leads to depolarization of the mitochondrial membrane and the release of cytochrome $\mathrm{C}$ and Smac/DIABLO into the cytosol and the formation of the apoptosome. In addition, NO-mediated inhibition of NF- $\mathrm{B}$ results in the inhibition of the transcription repressor, YY1, leading to upregulation of DR5 transcription and expression. Addition of TRAIL to NO-treated cells results in the complementation and in the activation of the mitochondrial pathway, resulting in the activation of caspases 9, 7 and 3 and leading to apoptosis.

In the DR5 promoter region, there is a binding site for YY1, which negatively regulates the transcription of DR5 expression. Studies have shown that TRAIL-resistant cells are able to become sensitive to TRAIL-mediated apoptosis via upregulation of DR5 expression via inhibition of YY1 (3). Various therapeutic drugs can interfere with DNA-binding activity of YY1 and subsequently increase the surface expression of DR5. Furthermore, upregulation of DR5 is correlated with sensitization of cells to TRAIL-induced apoptosis. Tests using siRNA against YY1 mRNA have confirmed the hypothesis that YY1 is a transcription repressor of DR5 and demonstrated its therapeutic potential as a pivotal player in inducing TRAIL-mediated apoptosis when used in combination with TRAIL (3). Likewise, NF- $\mathrm{KB}$, is associated in mediating apoptosis because inhibition of NF- $\mathrm{KB}$ results in inhibition of YY1 activity $(25,57)$. Upregulation of DR5 following inhibition of YY1 leads to apoptosis induced by TRAIL, and inhibition of NF- $\mathrm{NB}$ by different chemical agents also corresponds to overexpression of DR5 and sensitization to TRAIL-mediated apoptosis (31). Fig. 2 schematically represents the sensitization of TRAIL-resistant tumor cells by $\mathrm{NO}$ donors.

\section{Future directions/conclusions}

Unlike other members of the TNF family, TRAIL or agonist DR4/DR5 mAbs have the ability to selectively kill tumor cells while displaying minimal cytotoxicity on normal cells. The potential of TRAIL as an anti-tumor agent remains highly hopeful in TRAIL-sensitive cells when used alone or in TRAIL-resistant tumor cells when used in combination with low doses of chemotherapeutic drugs or NO donors whereby synergy is achieved. Bidil is a prescription medicine introduced by NitroMed in 1995 to treat patients with heartfailure and is composed of isosorbide dinitrate and hydralazine hydro-chloride, which are effective for arterial vasodilation. Although Bidil is mainly prescribed for treatment of cardiovascular diseases, it has the potential of being used as a NO donor because isosorbide dinitrate releases nitric oxide. Moreover, several NO donors have been synthesized that may sensitize resistant tumors to TRAIL-induced apoptosis or enhance the therapeutic potential of TRAIL via upregulation of death receptors, Snitrosylation of transcription factors, or activation of the mitochondrial pathway. In conclusion, we propose novel therapeutics involving a combination of TRAIL with DR4, 


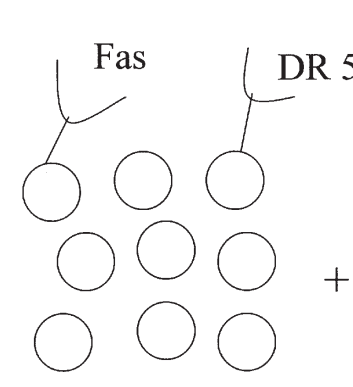

Tumor Cells
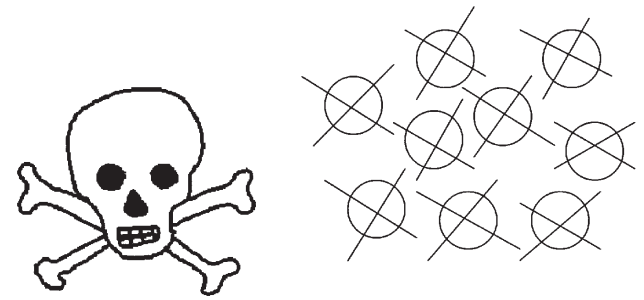

Tumor Cells

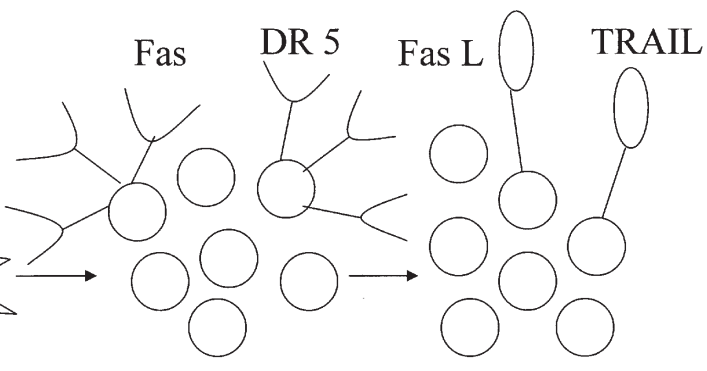

Tumor Cells

Host CTL, NK

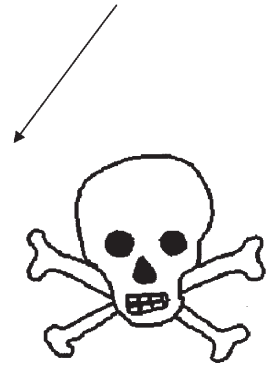

Figure 3. Potential in vivo immunotherapeutic activity of DETANONOate in combination with TRAIL. Tumor cells express low levels of Fas and DR5. When treated with the nitric oxide donor, DETANONOate, tumor cells express higher levels of Fas and DR5 and in the presence of host immune cells, CTL and NK, expressing FasL and TRAIL, it should result in killing of tumor cells via corresponding ligand receptor interactions.

DR5 mAbs NO donors that will mediate TRAIL-induced apoptosis and dysregulate pathways responsible for resistance. Hence, such combinations seem highly promising in the treatment of various resistant cancers. Alternatively, treatment with $\mathrm{NO}$ donors may be sufficient to regulate the sensitization of tumor cells to killing by host immune cells (such as CTL and NK), expressing apoptotic ligands (see schematic Fig. 3 for application in vivo).

\section{Acknowledgements}

The authors acknowledge the various investigators who have reported on the role of NO in tumor cell sensitization.

\section{References}

1. Bonavida B, Khineche S, Huerta-Yepez S and Garban H: Therapeutic potential of nitric oxide in cancer. Drug Resistance Updates 9: 157-173, 2006.

2. Shankar S, Chen X and Srivastava RK: Effects of sequential treatments with chemotherapeutic drugs followed by TRAIL on prostate cancer in vitro and in vivo. Prostate 62: 165-186, 2005.

3. Baritaki S, Huerta-Yepez S, Sakai T, Spandidos DA and Bonavida B: Chemotherapeutic drugs sensitize cancer cells to TRAIL-mediated apoptosis: up-regulation of DR5 and inhibition of Yin Yang 1. Mol Cancer Ther 6: 1387-1399, 2007.

4. Ng CP and Bondavida B: A new challenge for successful immunotherapy by tumors that are resistant to apoptosis; two complementary signals to overcome cross-resistance. Adv Cancer Res 85: 145-174, 2002.

5. Bonavida B: Overcoming cancer drug resistance: two signal hit model in cell signaling for apoptosis by combination of sensitizing agents and chemotherapy. In: Chemo-immunoensitization of Resistant Tumor Cells to Cell Death by Apoptosis. Bonavida B (ed). Transworld Research Network, Kerala, pp1-12, 2006.

6. Lee SH, Bar-Haim E, Machlenkin A, Goldberger O, Volovitz I, Vadai E, Tzehoval E and Eisenbach L: In vivo rejection of tumor cells dependent on CD8 cells that kill independently of perforin and FasL. Cancer Gene Ther 11: 237-248, 2004.
7. Kägi D, Vignaux F, Ledermann B, Bürki K, Depraetere V, Nagata S, Hengartner H and Golstein P: Fas and perforin pathways as major mechanisms of T cell-mediated cytotoxicity. Science 265: 528-530, 1994

8. Kägi D, Ledermann B, Bürki K, Seiler P, Odermatt B, Olsen KJ, Podack ER, Zinkernagel RM and Hengartner H: Cytotoxicity mediated by $\mathrm{T}$ cells and natural killer cells is greatly impaired in perforin-deficient mice. Nature 369: 31-37, 1994.

9. Smyth MJ, Thia KY, Street SE, MacGregor D, Godfrey DI and Trapani JA: Perforin-mediated cytotoxicity is critical for surveillance of spontaneous lymphoma. J Exp Med 192: 755-760, 2000.

10. Pitti RM, Marsters SA, Ruppert S, Donahue CJ, Moore A and Ashkenazi A: Induction of apoptosis by Apo-2 ligand, a new member of the tumor necrosis factor cytokine family. J Biol Chem 271: 12687-2690, 1996.

11. Wiley SR, Schooley K, Smolak PJ, Din WS, Huang CP, Nicholl JK, Sutherland GR, Smith TD, Rauch C, Smith CA, et al: Identification and characterization of a new member of the TNF family that induces apoptosis. Immunity 3: 673-682, 1995.

12. Shankar S and Srivastava RK: Enhancement of therapeutic potential of TRAIL by cancer chemotherapy and irradiation: mechanisms and clinical implications. Drug Resist Update 7: 139-156, 2004.

13. Kimberley FC and Screaton GR: Following a TRAIL: update on a ligand and its five receptors. Cell Res 14: 359-372, 2004

14. Bouralexis S, Findlay DM and Evdokiou A: Death to the bad guys: targeting cancer via Apo2L/TRAIL. Apoptosis 10: 35-51, 2005 .

15. Ashkenazi A, Pai RC, Fong S, Leung S, Lawrence DA, Marsters SA, Blackie C, Chang L, McMurtrey AE, Hebert A, De Forge L, Loumenis IL, Lewis D, Harris L, Bussiere J, Koeppen H, Shahrokh Z and Schwall RH: Safety and antitumor activity of recombinant soluble Apo2 ligand. J Clin Invest 104: 155-162, 1999.

16. De Jong S, Timmer T, Heijenbrok FJ and De Vries EG: Death receptor ligands, in particular TRAIL, to overcome drug resistance. Cancer Metastasis Rev 20: 51-56, 2001.

17. Wajant H, Pfizenmaier K and Scheurich P: TNF-related apoptosis inducing ligand (TRAIL) and its receptors in tumor surveillance and cancer therapy. Apoptosis 7: 449-459, 2002.

18. Chawla-Sarkar M, Bauer JA, Lupica JA, Morrison BH, Tang Z, Oates RK, Almasan A, Di Donato JA, Borden EC and Lidner DJ: Suppression of NF-kappa B survival signaling by nitrosylcobalamin sensitizes neoplasms to the anti-tumor effects of Apo2L/TRAIL. J Biol Chem 278: 39461-39469, 2003. 
19. Zisman A, Ng CP, Pantuck AJ, Bonavida B and Belldegrun AS: Actinomycin D and gemcitabine synergistically sensitize androgen-independent prostate cancer cells to Apo2L/TRAILmediated apoptosis. Immunotherapy 24: 459-471, 2001.

20. Bouralexis S, Findlay DM, Atkins GJ, Labrinidis A, Hay S and Evdokiou A: Progressive resistance of BTK-143 osteosarcoma cells to Apo2L/TRAIL-induced apoptosis is mediated by acquisition of DcR2/TRAIL-R4 expression: resensitisation with chemotherapy. Br J Cancer 89: 206-214, 2003.

21. Tillman DM, Izeradjene K, Szucs KS, Douglas L and Houghton JA: Rottlerin sensitizes colon carcinoma cells to tumor necrosis factor-related apoptosis-inducing ligand-induced apoptosis via uncoupling of the mitochondria independent of protein kinase C. Cancer Res 63: 5118-5125, 2003.

22. Munshi A, McDonnell TJ and Meyn RE: Chemotherapeutic agents enhance TRAIL-induced apoptosis in prostate cancer cells. Cancer Chemother Pharmacol 50: 46-52, 2002.

23. Park SY, Billiar TR and Seol DW: IFN-gamma inhibition of TRAIL-induced IAP-2 upregulation, a possible mechanism of IFN-gamma-enhanced TRAIL-induced apoptosis. Biochem Biophys Res Commun 291: 233-236, 2002.

24. Nyormoi O, Mills L and Bar-Eli M: An MMP-2/MMP-9 inhibitor, 5a, enhances apoptosis induced by ligands of the TNF receptor superfamily in cancer cells. Cell Death Differ 10: 558-569, 2003.

25. Huerta-Yepez S, Vega M, Jazirehi A, Garban H, Hongo F, Cheng $G$ and Bonavida B: Nitric oxide sensitizes prostate carcinoma cell lines to TRAIL-mediated apoptosis via inactivation of NF- $\kappa \mathrm{B}$ and inhibition of $\mathrm{Bcl}-\mathrm{X}_{\mathrm{L}}$ expression. Oncogene 23: 4993-5003, 2004.

26. Sheridan JP, Marsters SA, Pitti RM, et al: Control of TRAILinduced apoptosis by a family of signaling and decoy receptors. Science 277: 818-821, 1997.

27. Kischkel FC, Lawrence DA, Chuntharapai A, Schow P, Kim KJ and Ashkenazi A: Apo2L/TRAIL-dependent recruitment of endogenous FADD and caspase- 8 to death receptors 4 and 5 . Immunity 12: 611-620, 2000.

28. Ashkenazi A and Dixit VM: Death receptors: signaling and modulation. Science 281: 1305-1308, 1998.

29. Schulze-Osthoff K, Ferrari D, Los M, Wesselborg S and Peter ME: Apoptosis signaling by death receptors. Eur J Biochem 254: 439-459, 1998.

30. Rudner J, Jendrossek V, Lauber K, Daniel PT, Wesselborg S and Belka C: Type I and type II reactions in TRAIL-induced apoptosis - results from dose-response studies. Oncogene 24: 130-140, 2005

31. Ozoren N and El-Deiry WS: Defining characteristics of Types I and II apoptotic cells in response to TRAIL. Neoplasia 4: 551-557, 2002

32. Huang Y and Sheikh MS: TRAIL death receptors and cancer therapeutics. Toxicol Appl Pharmacol [Epub ahead of print] 2007.

33. Mariani SM, Matiba B, Armandola EA and Krammer PH: Interleukin 1 beta-converting enzyme related proteases/caspases are involved in TRAIL-induced apoptosis of myeloma and leukemia cells. J Cell Biol 137: 221-229, 1997.

34. Cretney E, Takeda K and Smyth M: Cancer: novel therapeutic strategies that exploit the TNF-related apoptosis-inducing ligand (TRAIL)/TRAIL receptor pathway. Int J Biochem Cell Biol 39: 280-286, 2007.

35. Hersh E, Metch BS, Muggia FM, Brown RD, Whitehead RP, Budd GT, et al: Phase II studies of recombinant human tumor necrosis factor alpha in patients with malignant disease: A Summary of the Southwest Oncology Group experience. J Immunother 10: 426-431, 1991.

36. Galle PR, Hofmann WJ, Walczak H, Schaller H, Otto G, Stremmel W, et al: Involvement of the CD95 (APO-1/Fas) receptor and ligand in liver damage. J Exp Med 182: 1223-1230, 1995.

37. Zou W, Liu X, Yue P, Zhou Z, Sporn MB, Lotan R, Khuri FR and Sun SY: c-Jun $\mathrm{NH}_{2}$-terminal kinase-mediated up-regulation of death receptor 5 contributes to induction of apoptosis by the novel synthetic triterpenoid methyl-2-cyano-3,12-dioxooleana1,9-dien-28-oate in human lung cancer cells. Cancer Res 64: 7570-7578, 2004.

38. Attard G, Plummer R, De Bono J, Bale C, Fong P, Barret M, et al: Phase I and pharmacokinetic study of HGS-ETR2, a fully human agonistic monoclonal antibody to TRAIL-R2, in patients with advanced solid malignancies. Proceedings of the AACRNCI-EORTC international conference. Mol Targets Cancer Therapeutics, Abst. B114, 2005.
39. Hirte H, Hotte S, Chen E, Siu L, Le L, Lo L, et al: HGS-ETR1, a fully human agonistic monoclonal antibody to the tumor necrosis factor-related apoptosis-inducing ligand receptor 1 (TRAIK-R1) in patients with advanced solid cancer: results of phase 1 trial. Proceedings of the AACR-NCI-EORTC international conference. Mol Targets Cancer Therapeutics, Abst. C22, 2005.

40. Sarantopoulos J, Wakelee H, Mita M, Fitzgerald A, Hill M, Fox N, et al: HGS-ETR2-ST02: a phase 1 clinical trial of HGSETR2, a fully human activating monoclonal antibody to TRAIL-R2, in patients with advanced solid tumors. Proceedings of the AACR-NCI-EORTC international conference. Mol Targets Cancer Therapeutics, Abst. C21, 2005.

41. Nagane M, Pan G, Weddle JJ, Dixit VM, Cavenee WK and Huang HJ: Increased death receptor 5 expression by chemotherapeutic agents in human gliomas causes synergistic cytotoxicity with tumor necrosis factor-related apoptosisinducing ligand in vitro and in vivo. Cancer Res 60: 847-853, 2000.

42. Muhlethaler-Mottet A, Bourloud KB, Auderset K, Joseph JM and Gross N: Drug-mediated sensitization to TRAIL-induced apoptosis in caspase-8-complemented neuroblastoma cells proceeds via activation of intrinsic and extrinsic pathways and caspase-dependent cleavage of XIAP, Bcl- $\mathrm{x}_{\mathrm{L}}$ and RIP. Oncogene 23: 5415-5425, 2004.

43. Micheau O, Hammann A, Solary E and Dimanche-Boitrel MT: STAT-1-independent upregulation of FADD and procaspase-3 and -8 in cancer cells treated with cytotoxic drugs. Biochem Biophys Res Commun 256: 603-607, 1999.

44. Lacour S, Micheau O, Hammann A, Drouineaud V, Tschopp J, Solary E and Dimanche-Boitrel MT: Chemotherapy enhances TNF-related apoptosis-inducing ligand DISC assembly in HT29 human colon cancer cells. Oncogene 22: 1807-1816, 2003.

45. Borst P and Rottenberg S: Cancer cell death by programmed necrosis. Drug Resist Update 7: 321-324, 2004

46. Garban HJ and Bonavida B: Nitric oxide sensitizes ovarian tumor cells to Fas-induced apoptosis. Gynecol Oncol 73: 257-264, 1998.

47. Blaise GA, Gauvin D, Gangal M and Authier S: Nitric oxide, cell signaling and cell death. Toxicology 208: 177-192, 2005.

48. Kleinert H, Pautz A, Linker K and Schwarz PM: Regulation of the expression of inducible nitric oxide synthase. Eur J Pharmacol 500: 255-266, 2004.

49. Ghosh S, May MJ and Kopp EB: NF-kappa B and Rel proteins: evolutionarily conserved mediators of immune responses. Annu Rev Immunol 16: 225-260, 1998.

50. Mukaida N, Mortia M, Ishikawa Y, Rice N, Okamoto S, Kasahara $\mathrm{T}$ and Matsushima K: Novel mechanism of glucocorticoid-mediated gene repression. Nuclear factor-kappa $\mathrm{B}$ is target for glucocorticoid-mediated interleukin 8 gene repression. J Biol Chem 269: 13289-13295, 1994.

51. Zech B, Kohl R, von Knethen A and Brune B: Nitric oxide donors inhibit formation of the Apaf-1/caspase-9 apoptosome and activation of caspases. Biochem J 371: 1055-1064, 2003.

52. Hongo F, Garban H, Huerta-Yepez S, Vega M, Jazirehi A, Mizutani Y, Miki T and Bonavida B: Inhibition of the transcription factor Yin Yang 1 activity by S-nitrosation. Biochem Biophys Res Commun 336: 692-701, 2005.

53. Hess DT, Matsumoto A, Kim SO, Marshall HE and Stamler JS: Protein S-nitrosylation: purview and parameters. Nat Rev Mol Cell Biol 6: 150-166, 2005.

54. Kroncke KD: Cysteine- $\mathrm{Zn}^{2+}$ complexes: unique molecular switches for inducible nitric oxide synthase-derived NO. FASEB J 15: 2503-2507, 2001

55. Shinyashiki M, Chiang KT, Switzer CH, Gralla EB, Valentine JS, Thiele DJ and Fukuto JM: The interaction of nitric oxide (NO) with the yeast transcription factor Ace1: a model system for NO-protein thiol interactions with implications to metal metabolism. Proc Natl Acad Sci USA 97: 2491-2496, 2000.

56. Seligson D, Horvath S, Huerta-Yepez S, Hanna S, Garban H, Roberts A, Shi T, Liu X, Chia D, Goodglick L and Bonavida B: Expression of transcription factor Yin Yang 1 in prostate cancer. Int J Oncol 27: 131-141, 2005.

57. Vega M, Huerta-Yepez S, Jazirehi AR, Garban H and Bonavida B: Rituximab (chimeric anti-CD20) sensitizes B-NHL cell lines to Fas-induced apoptosis. Oncogene 24: 8114-8127, 2005. 